Gousseau P, Blocken B, Stathopoulos, T, van Heijst GJF. 2011. CFD simulation of near-

field pollutant dispersion on a high-resolution grid: a case study by LES and RANS for a building group in downtown Montreal. Atmospheric Environment 45: 428-438

\title{
CFD simulation of near-field pollutant dispersion on a high- resolution grid: a case study by LES and RANS for a building group in downtown Montreal
}

\author{
P. Gousseau* $*^{\mathrm{a}}$, B. Blocken ${ }^{\mathrm{b}}$, T. Stathopoulos ${ }^{\text {c }}$, G.J.F. van Heijst ${ }^{\mathrm{d}}$ \\ ${ }^{a}$ Building Physics and Systems, Eindhoven University of Technology, P.O. Box 513, 5600 MB Eindhoven, The \\ Netherlands,p.gousseau@tue.nl \\ ${ }^{\mathrm{b}}$ Building Physics and Systems, Eindhoven University of Technology, P.O. Box 513, 5600 MB Eindhoven, The \\ Netherlands, b.j.e.blocken@tue.nl \\ ${ }^{\mathrm{c}}$ Building, Civil and Environmental Engineering, Concordia University, 1455 Blvd. de Maisonneuve West, \\ Montreal, Quebec, Canada, H3G1M8, statho@bcee.concordia.ca \\ ${ }^{\mathrm{d}}$ Fluid Dynamics Laboratory, Department of Physics, Eindhoven University of Technology, P.O. Box 513, 5600 \\ MB Eindhoven, The Netherlands, g.j.f.v.heijst@tue.nl
}

\begin{abstract}
Turbulence modeling and validation by experiments are key issues in the simulation of micro-scale atmospheric dispersion. This study evaluates the performance of two different modeling approaches (RANS standard k- $\varepsilon$ and LES) applied to pollutant dispersion in an actual urban environment: downtown Montreal. The focus of the study is on near-field dispersion, i.e. both on the prediction of pollutant concentrations in the surrounding streets (for pedestrian outdoor air quality) and on building surfaces (for ventilation system inlets and indoor air quality). The high-resolution CFD simulations are performed for neutral atmospheric conditions and are validated by detailed wind-tunnel experiments. A suitable resolution of the computational grid is determined by grid-sensitivity analysis. It is shown that the performance of the standard k- $\varepsilon$ model strongly depends on the turbulent Schmidt number, whose optimum value is case-dependent and a priori unknown. In contrast, LES with the dynamic subgrid-scale model shows a better performance without requiring any parameter input to solve the dispersion equation.
\end{abstract}

Keywords: Computational Fluid Dynamics (CFD); Large Eddy Simulation (LES); gas pollution; urban area; wind flow.

\section{Introduction}

Outdoor air pollution is associated with a broad spectrum of acute and chronic health effects (Brunekreef and Holgate, 2002). The pollutants that are brought into the atmosphere by various sources are dispersed (advected and diffused) over a wide range of horizontal length scales. Micro-scale dispersion refers to processes acting within horizontal length scales below about $5 \mathrm{~km}$. It can be studied in detail by wind-tunnel modeling and by numerical simulation with Computational Fluid Dynamics (CFD). Wind-tunnel modeling is widely recognized as a valuable tool in wind flow and gas dispersion analysis but it generally only provides data at a limited number of discrete positions and it can suffer from incompatible similarity requirements. CFD does not have these two disadvantages; it provides "whole flow-field" data and it can be performed at full scale. Furthermore, it is very suitable for parametric studies for various physical flow and dispersion processes. On the other hand, the accuracy of CFD is a main concern, and grid-sensitivity analysis and experimental validation studies are imperative.

In the past decades, CFD has been used extensively in micro-scale pollutant dispersion studies. A distinction can be made between generic studies and applied studies. Generic studies include configurations such as idealized isolated buildings (e.g. Leitl et al., 1997; Li and Stathopoulos, 1997; Meroney et al., 1999; Blocken et al., 2008; Tominaga and Stathopoulos, 2009; Santos et al., 2009), idealized isolated street canyons (e.g. Leitl and Meroney, 1997; Chan et al., 2002; Gromke et al., 2008) or regular building groups (e.g. Kim and Baik, 2004; Shi et al., 2008; Wang et al., 2009; Buccolieri et al., 2010; Dejoan et al., 2010). Applied studies refer to actual (isolated) buildings or actual building groups (urban areas) (e.g. Hanna et al., 2006; Patnaik et al., 2007; Baik et al., 2009; Pontiggia et al., 2010).

* Corresponding author: Pierre Gousseau, Building Physics and Systems, Eindhoven University of Technology, P.O. Box 513, 5600 MB Eindhoven, The Netherlands. Tel.: +31 (0)40 247 4374, Fax +31 (0)40 2438595

E-mail address: p.gousseau@tue.nl 
Many previous studies have indicated that CFD simulations based on the steady Reynolds-Averaged NavierStokes (RANS) equations are deficient in reproducing the wind-flow patterns (e.g. Murakami et al., 1992) and near-field pollutant dispersion concentrations around buildings (e.g. Leitl et al., 1997; Meroney et al., 1999; Blocken et al., 2008; Tominaga and Stathopoulos, 2010), which motivates the use of Large Eddy Simulation (LES) for micro-scale pollutant dispersion. A number of authors have applied LES to dispersion around isolated buildings (e.g. Tominaga et al., 1997; Sada and Sato, 2002) and in street canyons (e.g. Li et al., 2008; Hu et al., 2009). One of the main concerns in micro-scale atmospheric dispersion modeling, however, is determining the spread of pollutants from sources in actual urban environments. During the past decade, the continuous progress in computational power has allowed us to also apply LES to this kind of street-scale dispersion problems. An overview of previous LES studies in actual urban areas is provided in Table 1. For every study, the city name and location, the spatial extent of the urban study (near-field or far-field) and the subgrid-closure scheme are listed. It is also indicated whether RANS simulations were performed and whether validation by comparison with experiments was conducted. Finally, also the cell type and the grid resolution are reported. The present study aims at expanding the current state of the art in LES dispersion modeling, as discussed below.

The previous studies all involved a large group of buildings (13 or more) with the primary intention to determine the far-field spread of contaminants released from a source through the network of city streets and over buildings. This type of studies is called "far-field" dispersion studies in the framework of this paper. Given the extent of the computational domains involved, the grid resolutions in these far-field studies are generally relatively low, with a minimum cell size of the order of $1 \mathrm{~m}$. An exception to this is the study by Camelli et al. (2005), who used cell sizes down to $0.22 \mathrm{~m}$. Although the results provided by LES are generally promising, comparison with experimental data was only performed in two studies. For dispersion in actual urban areas, the relative performance of LES compared to RANS is not well known, as this was not addressed in previous studies.

Table 1

Up to now, to the knowledge of the authors, no high-resolution CFD studies of near-field gas dispersion for relatively large building groups which are accompanied by grid-sensitivity analysis and validation by comparison with experiments have been performed. The aim of this paper is to present this kind of study for pollutant dispersion around a building group in downtown Montreal. The focus is both on the prediction of pollutant concentrations in the surrounding streets (for pedestrian outdoor air quality) and on the prediction of concentrations on building surfaces (for ventilation system inlets placement and indoor air quality), i.e. two zones close to the source where the computation of the concentration distribution is known to be particularly challenging. The CFD simulations are validated by detailed wind-tunnel experiments performed earlier by Stathopoulos et al. (2004), in which sulfur-hexafluoride $\left(\mathrm{SF}_{6}\right)$ tracer gas was released from a stack on the roof of a three-storey building and concentrations were measured at several locations on this roof and on the facade of a neighboring high-rise building. Note that earlier CFD studies for the same case included none or only one of the neighboring buildings (Blocken et al., 2008; Lateb et al., 2010), while in the present study, surrounding buildings are included up to a distance of $300 \mathrm{~m}$. For this purpose, a high-resolution grid with minimum cell sizes down to a few centimeters (full-scale) is used. The grids are obtained based on detailed grid-sensitivity analysis. Both LES and RANS simulations are performed.

\section{Description of the experiments}

Experiments of pollutant dispersion in downtown Montreal were conducted in 2004 by Concordia University and $\operatorname{IRSST}^{1}$ (Stathopoulos et al., 2004). Two types of experiments were conducted: on-site and in the Concordia University boundary layer wind tunnel (Stathopoulos, 1984), with a scale factor of $1 / 200$. SF 6 was used as tracer gas and released from a stack located on the roof of the BE building, which is a three-storey building in the city center (Fig. 1). In the present study, the laboratory experiments are reproduced. The reason for this choice is the higher controllability of the boundary conditions offered by wind-tunnel modeling, which allows a more reliable evaluation of the CFD simulations. The dimensions are expressed at model scale unless specified otherwise.

Figure 1

The test section of the wind tunnel is $12.2 \mathrm{~m}$ long, $1.8 \mathrm{~m}$ high and $1.8 \mathrm{~m}$ wide. A combination of vortex generators and roughness elements along the test section floor allows the simulation of the atmospheric boundary layer $(\mathrm{ABL})$. The mean velocity profile of the neutral $\mathrm{ABL}$ is given by:

\footnotetext{
${ }^{1}$ Institut de recherche Robert-Sauvé en Santé et en Sécurité du Travail
} 


$$
\frac{U(z)}{U_{r e f}}=\left(\frac{z}{z_{r e f}}\right)^{\alpha}
$$

where the power-law exponent $\alpha$ is equal to 0.3 , corresponding to urban exposure; $U_{\text {ref }}=12.5 \mathrm{~ms}^{-1}$ is the mean wind velocity at reference height $z_{\mathrm{ref}}=0.6 \mathrm{~m}$ (full-scale: $120 \mathrm{~m}$ ); and $\mathrm{z}$ is the height above the ground. The streamwise turbulence intensity at the position of the model is $35 \%$ at ground level and $5 \%$ at reference height. The aerodynamic roughness length $\mathrm{z}_{0}$ is $0.0033 \mathrm{~m}$ and the longitudinal integral length scale $\mathrm{L}_{\mathrm{x}}$ is $0.4 \mathrm{~m}$.

Measurements were performed for different wind directions, stack locations, stack heights and momentum ratios. The two cases used for the validation study are summarized in Table 2 and illustrated in Figures $2 \mathrm{a}$ and 3a. In the table, $\theta$ is the angle between the north direction and the wind direction, as indicated in Figure $4, \mathrm{~h}_{\mathrm{s}}$ is the stack height and $\mathrm{M}$ is the momentum ratio defined as $\mathrm{M}=\mathrm{W}_{\mathrm{e}} / \mathrm{U}_{\mathrm{H}}$, where $\mathrm{W}_{\mathrm{e}}$ is the stack exhaust velocity and $\mathrm{U}_{\mathrm{H}}=6.5 \mathrm{~ms}^{-1}$ is the upstream undisturbed mean wind velocity at building height $(\mathrm{H}=6.8 \mathrm{~cm})$. The stack location numbering corresponds to that by Stathopoulos et al. (2004) where in total four stack locations were considered.

Table 2

Figure 2

Figure 3

For the south-west wind direction (Fig. 2a), the BE building is located immediately downstream of the highrise Faubourg building. It can be expected that plume dispersion will be strongly linked to the simulation of the recirculation zone in the wake of the Faubourg building. Concerning the westerly wind direction, the flow around the BE building will supposedly be influenced by the far wake of the two high-rise buildings upstream and the corner vortex of the Faubourg building. These two configurations have been selected because the abovementioned features make them highly challenging test cases for CFD simulation.

$\mathrm{SF}_{6}$ was released from the $2 \mathrm{~mm}$ diameter stack with a concentration of $10 \mathrm{ppm}$. In the wind tunnel, oneminute air samples were taken at several locations on the BE building roof, plus two locations at the top of the leeward facade of the Faubourg building in the case SW; the concentration was measured with a gas chromatograph with a precision of $\pm 5 \%$. The locations and labels of the measurement points for the two case studies are shown in Figure 4 together with the measured values of $100^{*} \mathrm{~K}$, where $\mathrm{K}$ is the non-dimensional concentration coefficient given by:

$$
K=\frac{\chi U_{H} H^{2}}{Q_{e}}
$$

In this equation, $\chi$ is the mean mass fraction of $\mathrm{SF}_{6}$ and $\mathrm{Q}_{\mathrm{e}}$ is the $\mathrm{SF}_{6}$ emission rate $\left(\mathrm{m}^{3} \mathrm{~s}^{-1}\right)$.

Figure 4

\section{Governing equations}

RANS turbulence models can provide accurate solutions for a wide range of industrial flow problems while requiring relatively low computational resources. The basic principle of this turbulence modeling approach is the application of the Reynolds-averaging operator to the Navier-Stokes equations, resulting in the appearance of new unknowns: the Reynolds stresses. These stresses can be linked to the flow variables in different ways, which defines the type of turbulence model.

With LES, a spatial filtering operator is used to separate two categories of motion scales. On the one hand, the large eddies are highly problem-dependent and are directly resolved. On the other hand, the smallest scales of motion are known to have a more universal behavior and their effect on the flow field can therefore be modeled by a so-called subgrid-scale (SGS) model. Contrary to steady RANS, the LES approach computes a timedependent solution; it is usually more demanding in terms of computational resources.

In this paper, the Eulerian approach is used to model the dispersion process for both RANS and LES methodologies. The concentration in $\mathrm{SF}_{6}$ is considered as a passive scalar transported by an advection-diffusion equation:

$$
\frac{\partial c}{\partial t}+\vec{u} \cdot \nabla c=D_{m} \nabla^{2} c+S
$$

where $\mathrm{c}$ is the mass concentration in $\mathrm{SF}_{6}\left(\mathrm{kgm}^{-3}\right)$; $\mathbf{u}$ is the velocity vector $\left(\mathrm{ms}^{-1}\right)$; $\mathrm{D}_{\mathrm{m}}$ is the molecular diffusion coefficient $\left(\mathrm{m}^{2} \mathrm{~s}^{-1}\right)$; and $\mathrm{S}$ is a source term $\left(\mathrm{kgm}^{-3} \mathrm{~s}^{-1}\right)$. 


\subsection{The RANS standard $k-\varepsilon$ model}

All the steady RANS simulations presented in this paper use the standard k- $\varepsilon$ turbulence model (SKE) (Jones and Launder, 1972). The intention is to test the ability of this widely used model to predict concentration distributions in complex geometries. In addition to the averaged momentum, continuity and energy equations, two other equations are solved for the transport of $\mathrm{k}$, the turbulent kinetic energy, and $\varepsilon$, the turbulent dissipation rate. SKE is used in combination with the Boussinesq hypothesis, which relates the Reynolds stresses to the mean-velocity gradients. This relation involves the turbulent viscosity $v_{\mathrm{t}}$, which can be calculated from $\mathrm{k}$ and $\varepsilon$.

When using SKE in the present study, all the transport equations are discretized using a second-order upwind scheme. Pressure interpolation is second order. The SIMPLE algorithm is used for pressure-velocity coupling. The gradients are computed in a discrete way, based on the Green-Gauss theorem (Fluent Inc., 2006). Convergence is assumed to be obtained when all the scaled residuals (Fluent Inc., 2006) reach 10 ${ }^{-6}$. The values of the model constants are: $\mathrm{C}_{1 \varepsilon}=1.44 ; \mathrm{C}_{2 \varepsilon}=1.92 ; \mathrm{C}_{\mu}=0.09 ; \sigma_{\mathrm{k}}=1.0 ; \sigma_{\varepsilon}=1.3$.

The application of the Reynolds-averaging operator to Eq. (3) leads to the appearance of the turbulent mass flux $\mathbf{q}_{\mathbf{t}}$ representing the effects of turbulence on mass transfer. Since in turbulent flows this flux largely dominates molecular diffusion, the accuracy of the concentration field prediction is strongly linked to the model used to determine $\mathbf{q}_{\mathbf{t}}$. By analogy with molecular diffusion, it is assumed to be proportional to the gradient of

mean concentration: $\mathbf{q}_{t}=-D_{t} \nabla C$, where $D_{t}$ is the turbulent mass diffusivity $\left(m^{2} s^{-1}\right)$ and $C$ is the mean

concentration $\left(\mathrm{kgm}^{-3}\right) . \mathrm{D}_{\mathrm{t}}$ is often assumed to be proportional to the turbulent viscosity. The relation involves a dimensionless parameter known as the turbulent Schmidt number $\left(S_{t}=v_{t} / D_{t}\right)$. Variations in the value of $S c_{t}$ are known to have a large influence on the concentration field (Tominaga and Stathopoulos, 2007; Blocken et al., 2008). In this study, three values of $\mathrm{Sc}_{\mathrm{t}}$ are used: $0.3,0.5$ and 0.7 , which are in the range of those used in previous studies (e.g. Tominaga and Stathopoulos, 2007; Blocken et al., 2008).

\subsection{Large Eddy Simulation}

In the filtered Navier-Stokes equations, the SGS stresses $\tau_{\mathrm{ij}}$ represent the effect of the small eddies on the resolved field of motion. In order to close the equations for the filtered velocity, the dynamic Smagorinsky SGS model (Smagorinsky, 1963; Germano et al., 1991; Lilly, 1992) is used in this study: the components of the deviatoric SGS stress tensor $\left(\tau_{\mathrm{ij}}{ }^{\mathrm{d}}\right)$ are linked to the filtered rate of strain by a linear relation:

$\tau_{i j}^{d}=-2 v_{s g s} \bar{S}_{i j}$

where $v_{\mathrm{sgs}}$ is the SGS turbulent viscosity $\left(\mathrm{m}^{2} \mathrm{~s}^{-1}\right)$ and $\overline{\mathrm{S}}_{\mathrm{ij}}=\left(\partial \overline{\mathrm{u}}_{\mathrm{i}} / \partial \mathrm{x}_{\mathrm{j}}+\partial \overline{\mathrm{u}}_{\mathrm{j}} / \partial \mathrm{x}_{\mathrm{i}}\right) / 2$ is the filtered rate of strain tensor.

The mixing-length hypothesis is used to evaluate the SGS turbulent viscosity:

$v_{s g s}=\left(C_{s} \Delta\right)^{2} \bar{S}$

where $\Delta$ is the filter width (m), equal to the cubic root of the computational cell volume, $\overline{\mathrm{S}}=\left(2 \overline{\mathrm{S}}_{\mathrm{ij}} \overline{\mathrm{S}}_{\mathrm{ij}}\right)^{1 / 2}$ is the characteristic filtered rate of strain and $\mathrm{C}_{\mathrm{s}}$ is the so-called Smagorinsky constant. In the present study, a dynamic procedure is used to evaluate this parameter, based on the resolved field. To avoid instabilities, the $\mathrm{C}_{\mathrm{s}}$ value is kept in the range [0; 0.23] (Fluent Inc., 2006).

In the LES computations in this paper, the momentum equation is discretized with a bounded central differencing scheme and a second-order upwind scheme is used for the energy and $\mathrm{SF}_{6}$ concentration equations. Pressure interpolation is second order. Time integration is second order implicit. The non-iterative fractional step method (Bell et al., 1989) is used for time advancement. This method allows reducing computational time by performing only a single outer iteration per time step. For the pressure equation, the sub-iterations end within a time step when the ratio of the residual at the current sub-iteration and the first sub-iteration is less than 0.25 , with a maximum of 10 sub-iterations per time step. For all the other equations, this ratio and this maximum are 0.05 and 5 , respectively.

The application of the filtering operator to Eq. (3) leads to the appearance of an SGS mass flux term $\mathbf{q}_{\mathbf{s g s}}$, which represents the effects of the scales that are smaller than the filter size on the resolved concentration field.

It is assumed to be proportional to the gradient of filtered concentration: $\mathbf{q}_{\mathbf{s g s}}=-\mathrm{D}_{\mathrm{sgs}} \nabla \overline{\mathrm{c}}$, where $\mathrm{D}_{\mathrm{sgs}}$ is the SGS

mass diffusivity $\left(\mathrm{m}^{2} \mathrm{~s}^{-1}\right)$. In the present study, this parameter is evaluated dynamically at each time step based on the resolved concentration field, in the same way as $\mathrm{C}_{\mathrm{s}}$. 


\section{Domain, grid and boundary conditions}

\subsection{Domain}

Two computational domains have been created, one for each wind direction (see Figures $2 \mathrm{~b}$ and $3 \mathrm{~b}$ ). The inlet and outlet planes are perpendicular to the flow direction, as required by the vortex method (Mathey et al., 2006) used to generate a time-dependent velocity profile at the inlet (more details in section 4.4). The streamwise, spanwise and vertical coordinates are denoted by $\mathrm{x}, \mathrm{y}$ and $\mathrm{z}$, respectively. The BE building is modeled in detail, including the roof-top structures. The other buildings are modeled based on the available full-scale data; they can therefore show some slight differences with the wind-tunnel model. Some simplifications are made to limit the number of cells and to make the simulations computationally "affordable": the vegetation is omitted (see Fig. 2a, on the left side), the side walls of the test section are not included as "walls" and, in the case SW, the most upstream buildings are not explicitly modeled because they are assumed to have limited influence on the plume dispersion. Note that in both case SW and W, at least one street block in each direction is explicitly modeled, in agreement with Tominaga et al. (2008b). The domain dimensions are based on the COST Action 732 guidelines (Franke et al., 2007). For case SW, the domain dimensions are $5 \times 2.125 \times 1.65 \mathrm{~m}^{3}$ (full-scale: $1000 \times 425 \times 330 \mathrm{~m}^{3}$ ) in $\mathrm{x}, \mathrm{y}, \mathrm{z}$ direction. For case $\mathrm{W}$, the domain dimensions are $5.75 \times 2.3 \times 1.65 \mathrm{~m}^{3}$ (full-scale: 1 150x460x330 $\mathrm{m}^{3}$ ).

\subsection{Computational grids}

The high-resolution computational grids are composed of hexahedral cells arranged in a horizontallyunstructured and vertically-structured way. They have been created by using the surface-grid extrusion technique by van Hooff and Blocken (2010). In the present study, the grid is first created in a horizontal plane and then swept in the vertical direction. This technique allows a large degree of control over cell shapes and sizes and avoids the use of tetrahedral and pyramid cells. For each case, RANS and LES are applied on the same computational grid. Previous numerical simulations of pollutant dispersion from a stack in a simple configuration (not presented here; see also Tominaga et al. (1997)) have shown the importance of meshing the outlet face of the stack with a high resolution. Hence, the range of cell dimensions is broad: from a few centimeters around the stack exhaust to several meters close to the boundaries of the domain, in full-scale dimensions. The ratio of two neighboring cell dimensions is kept around a value of 1.1.

For case SW, three different grid resolutions are used to analyze the grid sensitivity of the results. The medium grid, named SW-m, is composed of 4791744 cells. The stack circumference is divided into 32 segments. To ensure a reasonable aspect ratio of the cells around the stack exhaust, their vertical dimension is kept small. Because the grid includes the four stack locations, the resolution on the surface of the BE building is very high: 130x96x49 cells including the roof-top structures. The resolution of the grid on the neighboring buildings ranges from 0.005 to $0.015 \mathrm{~m}$ (full-scale: 1 to $3 \mathrm{~m}$ ), depending on the dimensions and the location of the building. In any case, a minimum of 10 cells per building height and between buildings in the horizontal plane has been used (Franke et al., 2007). Away from the area of interest, the grid size tends progressively to $0.04 \mathrm{~m}$ (full-scale: $8 \mathrm{~m}$ ). To analyze the effect of grid resolution on RANS and LES simulations, two additional computational grids are created: one finer (SW-f) and one coarser (SW-c). Refinement and coarsening are performed by multiplying the cell dimensions on the edges of the buildings by a constant factor (1.26 for SW-c and 0.8 for SW-f). For case SW-f, refinement is not performed farther than one street block away from the BE building to limit the total number of cells. The main grid characteristics are summarized in Table 3 .

Following the conclusions of the grid-sensitivity analysis for case SW (see Section 5.1), the computations for case SW are performed with grid SW-m, and those for case W with a grid with a similar resolution (named Wm) which contains 5257343 cells.

Table 3

\subsection{Boundary conditions}

With SKE, the profiles of $\mathrm{U}, \mathrm{k}$ and $\varepsilon$ are prescribed at the inlet of the domain, based on the measurements in the test section of the wind tunnel (see Section 2). To generate a time-dependent velocity profile with LES, the vortex method is used (Mathey et al., 2006). In the inlet plane, a given number $\mathrm{N}$ of vortices are generated and convected randomly at each time step. Their intensity and size depends on the local value of $\mathrm{k}$ and $\varepsilon$ whose profiles are prescribed at the inlet like for SKE. The fluctuations around the prescribed mean streamwise velocity are deduced from the perturbation caused by the vortices in the inlet plane. More details about this technique and validation studies can be found in Mathey et al. (2006). Previous studies on air flow around a wall-mounted cube 
(not presented here) have shown that the flow field can be simulated in an accurate way with $\mathrm{N}=190$; this value has therefore been retained for the present LES computations.

The exit face of the stack is defined as a velocity inlet with a uniform velocity profile. Turbulence quantities are computed based on the hydraulic diameter $\left(D_{h}=0.002 \mathrm{~m}\right)$ and an assumed value of turbulence intensity of $10 \%$.

At the top and lateral boundaries, symmetry boundary conditions are prescribed. At the outlet plane, zero static pressure is imposed. All building surfaces are defined as smooth no-slip walls. For simulations with the SKE turbulence model, the standard wall functions (Launder and Spalding, 1974) are applied to compute the variables - including $\mathrm{c}$ - in the wall-adjacent cells. For case $\mathrm{SW}-\mathrm{m}$, the maximum value of $\mathrm{y}^{*}$ on the building walls is equal to $830\left(\mathrm{y}^{*}=\mathrm{C}_{\mu}{ }^{1 / 4} \mathrm{k}_{\mathrm{P}}{ }^{1 / 2} \mathrm{Z}_{\mathrm{P}} / \mathrm{v}\right.$, where $\mathrm{k}_{\mathrm{P}}$ is the value of $\mathrm{k}$ at the centroid $\mathrm{P}$ of the wall-adjacent cells, $\mathrm{z}_{\mathrm{P}}$ is the height of $\mathrm{P}$ and $v$ is the kinematic viscosity of the fluid). However, in a large majority of the cells, $\mathrm{y}^{*}$ is below 300, which justifies the use of the wall functions. With LES, the centroids of the wall-adjacent cells are assumed to fall in the logarithmic law region of the boundary layer (Fluent Inc., 2006).

The ground is defined as a rough wall boundary to take into account the effects of the surrounding terrain (i.e. all the buildings that are not explicitly modeled in the computational domain) on the ABL flow. With SKE and the standard wall functions, the roughness of the wall is characterized by the sand-grain roughness height $\mathrm{k}_{\mathrm{s}}$ (m) and the roughness constant $\mathrm{C}_{\mathrm{r}}$. In order to limit the longitudinal gradients which occur because of the incompatibility of the wall functions with the $\mathrm{ABL}$ profiles, these parameters are chosen according to the relation $\mathrm{k}_{\mathrm{s}}=9.793 \mathrm{z}_{0} / \mathrm{C}_{\mathrm{r}}$ (Blocken et al., 2007), where $\mathrm{k}_{\mathrm{s}}$ is taken smaller than $\mathrm{z}_{\mathrm{P}}\left(\mathrm{e} . \mathrm{g} . \mathrm{z}_{\mathrm{P}}=0.00125 \mathrm{~m}\right.$ for SW-m and W$\mathrm{m})$. In Fluent 6.3, a too high input value of $\mathrm{C}_{\mathrm{r}}$ can create numerical instabilities so in this case where $\mathrm{z}_{0}$ is high and $k_{s}$ is low (e.g. $k_{s}=0.0012 \mathrm{~m}$ for $\mathrm{SW}-\mathrm{m}$ and $\mathrm{W}-\mathrm{m}$ ), the $\mathrm{C}_{\mathrm{r}}$ value is bounded to 7 . Therefore, some longitudinal gradients will occur. The wall treatment used with LES in Fluent does not take into account the roughness of the wall. To limit the longitudinal gradients of the inflow profiles in both the RANS and LES simulations, the upstream length of the domain has been kept intentionally short (around $0.3 \mathrm{~m}$ ). In addition, it is reasonable to assume that the flow patterns around the BE building are to a large extent determined by the neighboring buildings and that the influence of the short-fetch upstream degradation of ABL flow is low.

\subsection{Unsteady parameters for LES}

As pointed out in section 4.2, the large dimensions of the domain combined with the necessity to refine the grid around the source location lead to heterogeneous cells dimensions in the computational grid. On the one hand, the time step size is usually limited by the dimensions of the smallest cells. On the other hand, the large dimensions of the domain require a long averaging time to get a statistically-steady solution: several "flowthrough" time units $\left(\mathrm{T}=\mathrm{L} / \mathrm{U}_{\text {ref }}\right.$ where $\mathrm{L}$ is the domain dimension in the streamwise direction) are generally used. In practice, satisfying these two conditions is not affordable in terms of computational time and a compromise must be made.

For the medium grid, the time step is set to $\Delta \mathrm{t}=5.10^{-4} \mathrm{~s}$, which leads to a Courant number $(=\mathrm{u} \Delta \mathrm{t} / \mathrm{h}$, where $\mathrm{u}$ is the local velocity magnitude and $\mathrm{h}$ is the local grid size) below one in the majority of the cells. This value corresponds to the scaled-down model; the equivalent time step at full scale with the same reference velocity is $0.1 \mathrm{~s}$. The grid-sensitivity analysis was performed at constant Courant number: the time step has been increased to $6.3 .10^{-4} \mathrm{~s}$ for grid SW-c and decreased to $4.10^{-4} \mathrm{~s}$ for grid SW-f.

The LES computations are initialized with the solution from the SKE simulations. Before averaging, the computation is run during $2 \mathrm{~s}$ to remove the influence of the initial condition. Then, data are averaged over a period of $4 \mathrm{~s}$ (full-scale: $800 \mathrm{~s}$ ), corresponding to 10T. The monitored evolution of $\mathrm{K}$ with time (moving average) at the measurement points indicates that this period is long enough to get statistically steady values, although it is smaller than the averaging time in the wind tunnel.

\section{Results and discussion}

\subsection{Grid-sensitivity analysis for case $S W$}

The results of the simulations performed on the grids SW-c, SW-m and SW-f with SKE and $\mathrm{Sc}_{\mathrm{t}}=0.5$ are shown in Figure 5a, where the concentration values obtained with the coarse and fine grids (vertical axis) are compared to those on the medium grid (horizontal axis). A slight change in the results can be observed from SW-c to SW$\mathrm{m}$, whereas the results obtained with SW-m and SW-f are similar.

In the case of LES with implicit filtering, the local filter width is equal to the computational cell size. As a consequence, the LES model is in essence grid dependent and the conclusions of the grid-sensitivity analysis are less straightforward than in the RANS case. In particular, it is known that a grid-independent solution cannot be found (Klein, 2005). As can be seen in Figure 5b, it appears that the values predicted with SW-c are lower than those predicted with SW-m. In contrast, the use of the grid SW-f leads to a slight increase of the concentration 
values, especially at the points of lower concentration. It is argued that this slight difference does not justify the large increase in computational time required with SW-f. Thus, in the next section, the results of SW-m will be presented and a resolution similar to SW-m was adopted for the study of case W.

Figure 5

\subsection{Comparison between standard $k-\varepsilon$ and LES on medium grid for case $S W$}

The values of non-dimensional concentration $(100 * \mathrm{~K})$ obtained with the numerical simulations are compared to the wind-tunnel results in the scatter plots of Figure 6. With SKE, it is clear that - as expected - variations of $\mathrm{Sc}_{\mathrm{t}}$ can have a large influence on the concentration values (Fig. 6a). No large discrepancies are observed with LES: except for point 15 (on the Faubourg building), the computed $\mathrm{K}$ values are within a factor of three from the wind-tunnel measurements (Fig. 6b). It should also be noted that, except for point 9 (close from the stack), the values of $\mathrm{K}$ provided by the LES computation are all under-estimated compared to the experiment.

Figure 6

The average $\left(\mathrm{e}_{\mathrm{AVG}}\right)$, maximum ( $\left.\mathrm{e}_{\mathrm{MAX}}\right)$ and median ( $\left.\mathrm{e}_{\mathrm{MED}}\right)$ values of the relative error over all the data points are given in Table 4 . The relative error $e(\%)$ is defined for each data point by:

$$
e=100 * \frac{\left|K_{E x p}-K_{C F D}\right|}{K_{E x p}}
$$

where $\mathrm{K}_{\mathrm{Exp}}$ and $\mathrm{K}_{\mathrm{CFD}}$ are the measured and computed values of the concentration coefficient, respectively. The lowest values of $\mathrm{e}_{\mathrm{AVG}}$ and $\mathrm{e}_{\mathrm{MAX}}$ with $\mathrm{SKE}$ are obtained with $\mathrm{Sc}_{\mathrm{t}}=0.7$; $\mathrm{e}_{\mathrm{MAX}}$ remains high, however. With LES, both $\mathrm{e}_{\mathrm{AVG}}$ and $\mathrm{e}_{\mathrm{MAX}}$ are low, and $\mathrm{e}_{\mathrm{MED}}$ is very close to the average value, which shows the symmetric distribution of the error values around $\mathrm{e}_{\mathrm{AVG}}$. By contrast, $\mathrm{e}_{\mathrm{MED}}<\mathrm{e}_{\mathrm{AVG}}$ for SKE denotes a skewed distribution of the error values and the presence of outliers. Indeed, Table 5 shows that the value of e at point 9 (close to the stack) is very high.

Table 4

Table 5

Figure 7 shows the contours of non-dimensional mean streamwise velocity $\left(U / U_{\text {ref }}\right)$ in the vertical plane $y=$ $\mathrm{y}_{\text {stack }}$ which is aligned with the flow direction and contains the center of the stack. In accordance with previous numerical simulations for simplified building models (e.g. Murakami et al., 1992; Tominaga et al., 2008a), the recirculation zone in the wake of the Faubourg building (denoted by A) extends farther downstream with SKE than with LES because of the under-estimation by SKE of the turbulent kinetic energy at this location. In this region, the backflow tends to transport the pollutant towards the Faubourg building. Indeed, with both models, the maximum concentrations occur on the leeward facade of the Faubourg building (Fig. 8) and the concentration values on the building surfaces and the surrounding streets predicted with LES (Fig. 8b) are overall lower than those predicted with SKE with $\mathrm{Sc}_{\mathrm{t}}=0.7$ (Fig. 8a). However, on the roof of the Faubourg building, LES predicts high concentration values. This is not the case with SKE, and is attributed to the fact that this model does not reproduce the roof-top separation and recirculation zone B (Fig. 7).

Figure 7

Figure 8

\subsection{Comparison between standard $k-\varepsilon$ and LES on medium grid for case $W$}

Figure 9a shows that the simulations of case $\mathrm{W}$ with SKE show a poor agreement with the measurements. The discrepancy between CFD and experiments is minimal for $\mathrm{Sc}_{t}=0.3$, as confirmed by the relative errors shown in Table 6. Figure $9 \mathrm{~b}$ shows the scatter plots for the LES computation. Although maximum errors remain large, on average the accuracy is improved: the average relative error drops to $66.8 \%$ (Table 6).

Figure 9

Table 6

The contours of $100 * \mathrm{~K}$ on the building roofs and on the surrounding streets are shown in Figure 10. With $\mathrm{SKE}$, the horizontal spread of the plume increases as the value of $\mathrm{Sc}_{\mathrm{t}}$ decreases (not shown in the figure). Among the three values tested here, this spread is maximal for $\mathrm{Sc}_{\mathrm{t}}=0.3$ (Fig. 10a). Figure 10b shows that it is even 
higher with LES, resulting in higher concentration levels at the downstream neighboring streets. Note that with both models the centerline of the plume is not aligned with the wind-flow direction: the complex interaction of the oncoming wind-flow with the buildings and the elevated rooftop structures of the BE building results in a velocity component in the y-direction at the location of the stack, which tends to deviate the plume. It seems that this deviation was not observed in the wind tunnel since the concentration values at the points located in the zone $\mathrm{y} \leq \mathrm{y}_{\text {stack }}$ (namely: points $6,9,10,13$, and 14; see Table 7) are largely underestimated by the numerical simulations. This can likely be attributed to the complex combination of vortex shedding from the Faubourg building and the long roof-top structure on the BE building. Small deviations in reference wind direction are expected to have a large influence here. Another high discrepancy occurs at point 1, very close to the stack, which appears to be one of the most difficult locations to predict.

Figure 10

Table 7

\subsection{Discussion}

Numerical simulation of atmospheric dispersion in urban environments is difficult and the selected turbulence modeling approach largely determines the quality of the results.

In the present study, the case where the BE building is located in the wake of a high-rise building (case SW) shows the best agreement between CFD and experiments, especially with LES. In this case, the pollutant is transported towards the leeward facade of the Faubourg building. From a practical point of view, if this wind direction is likely to occur often (which is the case in reality; see Stathopoulos et al. (2004)), ventilation intakes of the Faubourg building should preferably not be located on this facade and, according to the LES results, also not on the roof or the sides of the building. Pollutants can also contaminate the indoor air of the Faubourg building if the windows of the leeward facade are open. Air quality can deteriorate in the street between the BE and Faubourg buildings (Fig. 8) and this can affect pedestrians. Why the concentration values predicted with LES are generally under-estimated compared to the experiment is not totally clear. A possible reason is the way in which the concentration is computed in the cells adjacent to the building surfaces, where all data points are located. Further investigation of near-wall modeling effects on surface concentration predictions is required.

Also for case W, LES provides more accurate concentration values on the roof of the BE building than SKE. For this wind direction, the plume trajectory is less disturbed than for case SW. The buildings located downstream will be affected by pollution. The horizontal spread of pollutant is high and the streets located in a wide region downstream of the BE building will be polluted as well. The numerical simulations also indicate a deviation of the plume which is considered to be responsible for the significant under-estimation of $\mathrm{K}$ at the points located in the zone $\mathrm{y} \leq \mathrm{y}_{\text {stack }}$.

For both wind directions under study, it was verified that the results of the SKE simulations are highly dependent on the value of $\mathrm{Sc}_{\mathrm{t}}$. Moreover, its optimum is a priori unknown and strongly case-dependent. For example, among the three values tested, the best value is 0.7 for case $\mathrm{SW}$ and 0.3 for case W. By contrast, LES with the dynamic Smagorinsky SGS model and the dynamic computation of $\mathrm{D}_{\text {sgs }}$ can provide more accurate results without any parameter input to solve the dispersion equation. This is considered a main advantage of the LES approach.

Because it is an unsteady model, LES can also provide the extreme values of the concentration everywhere in the domain. From a practical point of view, this information will be required when dealing with hazardous materials whose concentration must not exceed a certain threshold. However, LES is approximately seven times more demanding in terms of computational cost than SKE in this study where the same grid has been used for both RANS and LES. LES is also very sensitive to the type and resolution of the computational grid used; in the present study, the refinement of the grid has led to an increase in the computed concentration values. Finally, it should be emphasized that wind-tunnel experiments providing both velocity and concentration measurements in an actual urban environment would be of great interest for further evaluation and comparison of turbulence models applied to atmospheric dispersion problems.

\section{Summary and conclusions}

High-resolution CFD simulation of near-field pollutant dispersion in a building group in downtown Montreal was performed with two different turbulence modeling approaches: RANS standard k- $\varepsilon$ and LES with the dynamic Smagorinsky SGS model. Contrary to most of the previous CFD studies of urban dispersion which focused on the far-field spread of contaminants, the present simulations focused on the concentration values close to the source (on the building surfaces and in the surrounding streets) and were performed on highresolution grids. They were validated by comparison with wind-tunnel measurements for two different wind directions: south-west, for which a high-rise building is located immediately upstream of the emitting building, 
and west, for which the obstacles are located farther upstream. Both RANS and LES computations were performed on the same grids. The grid-sensitivity analysis indicated that the medium grid SW-m was suitable for the problem. For this grid, the stack circumference was divided into 32 segments, the BE building was discretized into 130x96x49 cells and a full-scale resolution of 1.5 to $3 \mathrm{~m}$ was used for the neighboring buildings. The agreement between numerical simulations and wind-tunnel measurements was good in the case SW but larger discrepancies were observed in the case W. Nevertheless, LES was better in both cases and has the advantage of solving the dispersion equation without any parameter input when the SGS mass diffusivity $\mathrm{D}_{\mathrm{sgs}}$ is computed with a dynamic procedure. The simulation by the numerical model of the flow separation at the sharp edges of the buildings appears to be crucial for the proper simulation of the concentration field. Future work will consist of testing the ability of various turbulence modeling approaches and turbulence models to accurately reproduce flow separation on computationally affordable grids for generic cases including isolated buildings and street canyons. It will also include investigation of the influence of small deviations in wind direction on the concentration field.

\section{Acknowledgements}

The numerical simulations reported in this paper were supported by the laboratory of the Unit Building Physics and Systems (BPS) of Eindhoven University of Technology.

\section{References}

Baik J.J., Park S.B., Kim J.J., 2009. Urban flow and dispersion simulation using a CFD model coupled to a mesoscale model. Journal of Applied Meteorology and Climatology 48(8), 1667-1681.

Bell J.B., Glaz H.M., Colella P., 1989. Second-order projection method for the incompressible Navier-Stokes equations. Journal of Computational Physics 85, 257-283.

Blocken B., Stathopoulos T., Carmeliet J., 2007. CFD simulation of the atmospheric boundary layer: wall function problems. Atmospheric Environment 41, 238-252.

Blocken B., Stathopoulos T., Saathoff P., Wang X., 2008. Numerical evaluation of pollutant dispersion in the built environment: Comparisons between models and experiments. Journal of Wind Engineering and Industrial Aerodynamics 96, 1817-1831.

Brunekreef B., Holgate S.T., 2002. Air pollution and health. Lancet 360, 1233-1242.

Buccolieri R., Sandberg M., Di Sabatino S., 2010. City breathability and its link to pollutant concentration distribution within urban-like geometries. Atmospheric Environment 44(15), 1894-1903.

Camelli F.E., Löhner R., Hanna S.R., 2005. Dispersion patterns in a heterogeneous urban area, in: Larreteguy A. (Ed.), Mecánica Computacional Vol. XXIV, Buenos Aires, Argentina, pp. 1339-1354.

Chan T.L., Dong G., Leung C.W., Cheung C.S., Hung T.W., 2002. Validation of a two-dimensional pollutant dispersion model in an isolated street canyon. Atmospheric Environment 36(5), 861-872.

Dejoan A., Santiago J.L., Martilli A., Martin F., Pinelli A., 2010. Comparison between large-eddy simulation and Reynolds-averaged Navier-Stokes computations for the MUST field experiment. Part II: Effects of incident wind angle deviation on the mean flow and plume dispersion. Boundary-Layer Meteorology 135, $133-150$

Fluent 6.3 User's Guide, Fluent Inc., Lebanon, 2006

Franke J., Hellsten A., Schlünzen H., Carissimo B., 2007. Best practice guideline for the CFD simulation of flows in the urban environment. COST Action 732.

Germano M., Piomelli U., Moin P., Cabot W.H., 1991. A dynamic subgrid-scale eddy viscosity model. Physics of Fluids A 3, 1760-1765.

Gromke C., Buccolieri R., Di Sabatino S., Ruck B., 2008. Dispersion study in a street canyon with tree planting by means of wind tunnel and numerical investigations - Evaluation of CFD data with experimental data. Atmospheric Environment 42(37), 8640-8650.

Hanna S.R., Brown M.J., Camelli F.E., Chan S.T., Coirier W.J., Hansen O.R., Huber A.H., Kim S., Reynolds R.M., 2006. Detailed simulations of atmospheric flow and dispersion in downtown Manhattan. An application of five computational fluid dynamics models. Bulletin of the American Meteorological Society 87, 1713-1726.

Hu L.H., Huo R., Yang D., 2009. Large eddy simulation of fire-induced buoyancy driven plume dispersion in an urban street canyon under perpendicular wind flow. Journal of Hazardous Materials 166, 394-406.

Jones W.P., Launder B.E., 1972. The prediction of laminarization with a two-equation model of turbulence. International Journal of Heat and Mass Transfer 15, 301-314.

Kim J.J., Baik J.J., 2004. A numerical study of the effects of ambient wind direction on flow and dispersion in urban street canyons using the RNG k- $\varepsilon$ turbulence model. Atmospheric Environment 38(19), 3039-3048.

Klein M., 2005. An attempt to assess the quality of large eddy simulations in the context of implicit filtering. Flow, Turbulence and Combustion 75, 131-147. 
Lateb M., Masson C., Stathopoulos T., Bédard C., 2010. Numerical simulation of pollutant dispersion around a building complex. Building and Environment 45, 1788-1798.

Launder B.E., Spalding D.B., 1974. The numerical computation of turbulent flows. Computer Methods in Applied Mechanics and Engineering 3, 269-289.

Leitl B.M., Meroney R., 1997. Car exhaust dispersion in a street canyon. Numerical critique of a wind tunnel experiment. Journal of Wind Engineering and Industrial Aerodynamics 67 \& 68, 293-304.

Leitl B.M., Kastner-Klein P., Rau M., Meroney R.N., 1997. Concentration and flow distributions in the vicinity of U-shaped buildings: wind-tunnel and computational data. Journal of Wind Engineering and Industrial Aerodynamics $67 \& 68,745-755$.

Li X.-X., Liu C.-H., Leung D.Y.C., 2008. Large-eddy simulation of flow and pollutant dispersion in high-aspectratio urban street canyons with wall model. Boundary-Layer Meteorology 129, 249-268.

Li Y., Stathopoulos T., 1997. Numerical evaluation of wind-induced dispersion of pollutants around a building. Journal of Wind Engineering and Industrial Aerodynamics 67 \& 68, 757-766.

Lilly D.K., 1992. A proposed modification of the Germano subgrid-scale closure method. Physics of Fluids A 4, 633-635.

Mathey F., Cokljat D., Bertoglio J.-P., Sergent E., 2006. Assessment of the vortex method for large eddy simulation inlet conditions. Progress in Computational Fluid Dynamics 6, 58-67.

Meroney R.N., Leitl B.M., Rafailidis S., Schatzmann M., 1999. Wind-tunnel and numerical modeling of flow and dispersion about several building shapes. Journal of Wind Engineering and Industrial Aerodynamics 81, 333-345.

Murakami S., Mochida A., Hayashi Y., Sakamoto S., 1992. Numerical study on velocity-pressure field and wind forces for bluff bodies by k- $\varepsilon$, ASM and LES. Journal of Wind Engineering and Industrial Aerodynamics 4144, 2841-2852.

Patnaik G., Boris J.P., Young T.R., 2007. Large scale urban contaminant transport simulations with Miles. Journal of Fluids Engineering 129, 1524-1532.

Pontiggia M., Derudi M., Alba M., Scaioni M., Rota R., 2010. Hazardous gas releases in urban areas: assessment of consequences through CFD modelling. Journal of Hazardous Materials 176, 589-596.

Sada K., Sato A., 2002. Numerical calculation of flow and stack-gas concentration fluctuation around a cubical building. Atmospheric Environment 36, 5527-5534.

Santos J.M., Reis N.C., Goulart E.V., Mavroidis I., 2009. Numerical simulation of flow and dispersion around an isolated cubical building: The effect of the atmospheric stratification. Atmospheric Environment 43(34), 5484-5492.

Shi R.F., Cui G.X., Wang Z.S., Xu C.X., Zhang Z.S., 2008. Large eddy simulation of wind field and plume dispersion in building array. Atmospheric Environment 42, 1083-1097.

Smagorinsky J., 1963. General circulation experiments with the primitive equations. I. The basic experiment. Monthly Weather Review 91, 99-164.

Stathopoulos T., 1984. Design and fabrication of a wind tunnel for building aerodynamics. Journal of Wind Engineering and Industrial Aerodynamics 16, 361-376.

Stathopoulos T., Lazure L., Saathoff P., Gupta A., 2004. The effect of stack height, stack location and roof-top structures on air intake contamination - A laboratory and full-scale study. IRSST report R-392, Montreal, Canada, 2004.

Tamura T., Nakayama H., Okuda Y., 2006. LES analysis on atmospheric dispersion in spatially-developing turbulent boundary layer in actual urban area. Journal of Environmental Engineering (Transactions of AIJ) 604, 31-38.

Tamura T., 2008. Towards practical use of LES in wind engineering. Journal of Wind Engineering and Industrial Aerodynamics 96, 1451-1471.

Tominaga Y., Murakami S., Mochida A., 1997. CFD prediction of gaseous diffusion around a cubic model using a dynamic mixed SGS model based on composite grid technique. Journal of Wind Engineering and Industrial Aerodynamics 67\&68, 827-841.

Tominaga Y., Stathopoulos T., 2007. Turbulent Schmidt numbers for CFD analysis with various types of flowfield. Atmospheric Environment 41, 8091-8099.

Tominaga Y., Mochida A., Murakami S., Sawaki S., 2008a. Comparison of various revised k- $\varepsilon$ models and LES applied to flow around a high-rise building model with 1:1:2 shape placed within the surface boundary layer. Journal of Wind Engineering and Industrial Aerodynamics 96, 389-411.

Tominaga Y., Mochida A., Yoshie R., Kataoka H., Nozu T., Yoshikawa M., Shirasawa T., 2008b. AIJ guidelines for practical applications of CFD to pedestrian wind environment around buildings. Journal of Wind Engineering and Industrial Aerodynamics 96, 1749-1761.

Tominaga Y., Stathopoulos T., 2009. Numerical simulation of dispersion around an isolated cubic building: Comparison of various types of k- $\varepsilon$ models. Atmospheric Environment 43(20), 3200-3210. 
Tominaga Y., Stathopoulos T., 2010. Numerical simulation of dispersion around an isolated cubic building: model evaluation of RANS and LES. Building and Environment 45(10), 2231-2239.

Tseng Y.-H., Meneveau C., Parlange M.B., 2006. Modeling flow around bluff bodies and predicting urban dispersion using large eddy simulation. Environmental Science \& Technology 40, 2653-2662.

Van Hooff T., Blocken, B., 2010. Coupled urban wind flow and indoor natural ventilation modelling on a highresolution grid: A case study for the Amsterdam ArenA stadium. Environmental Modelling \& Software 25, 51-65.

Wang B.C., Yee E., Lien F.S., 2009. Numerical study of dispersing pollutant clouds in a built-up environment. International Journal of Heat and Fluid Flow 30, 3-19.

Xie Z.-T., Castro I.P., 2009. Large-eddy simulation for flow and dispersion in urban streets. Atmospheric Environment 43, 2174-2185. 


\section{FIGURE CAPTIONS}

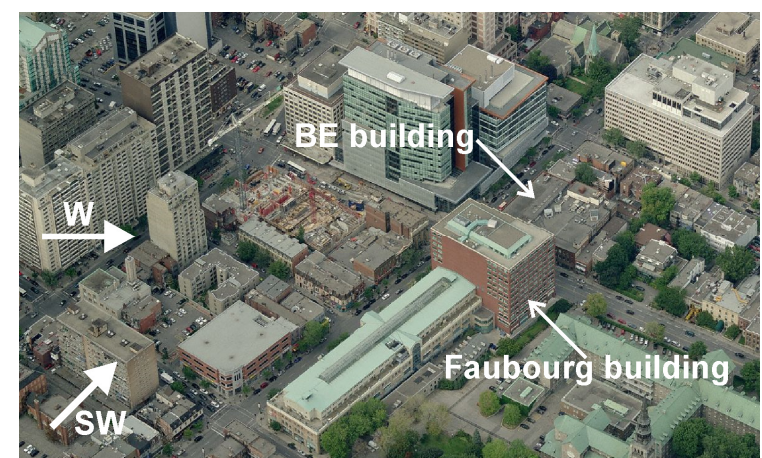

Fig. 1. View from south of the BE building and its surroundings in downtown Montreal and wind directions considered in the present study.
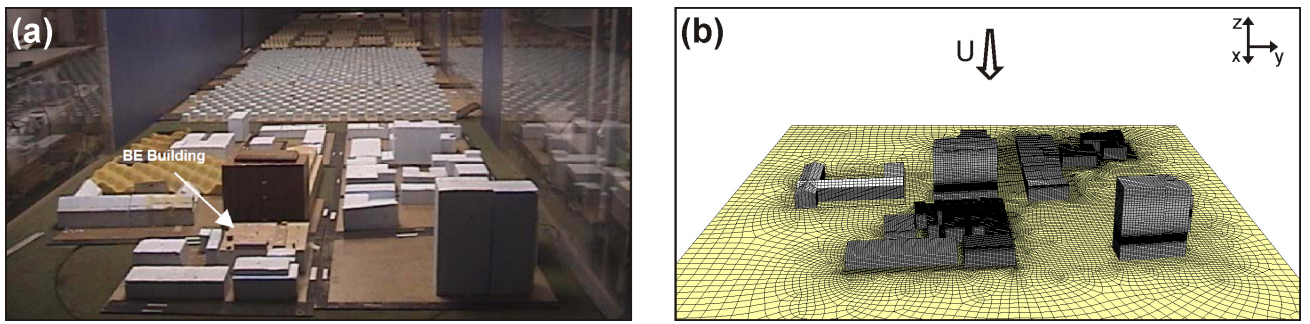

Fig. 2. Case SW: (a) wind-tunnel model and (b) corresponding computational grid on the building and ground surfaces.
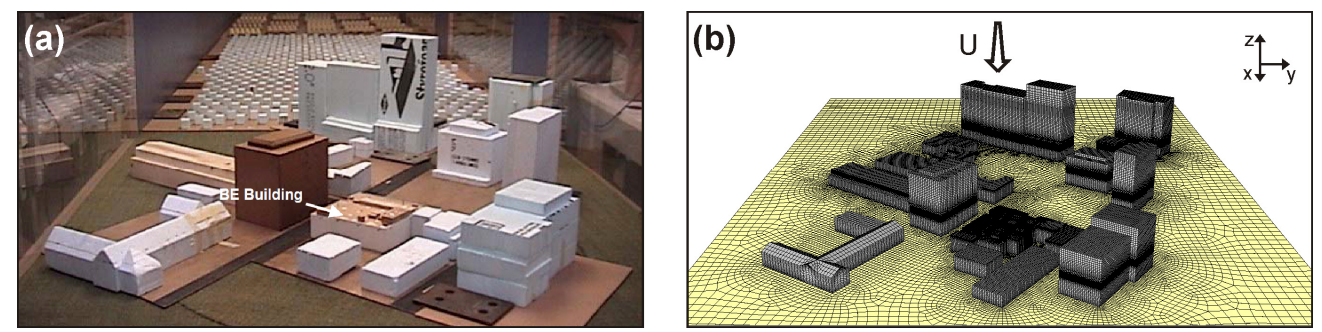

Fig. 3. Case W: (a) wind-tunnel model and (b) corresponding computational grid on the building and ground surfaces.

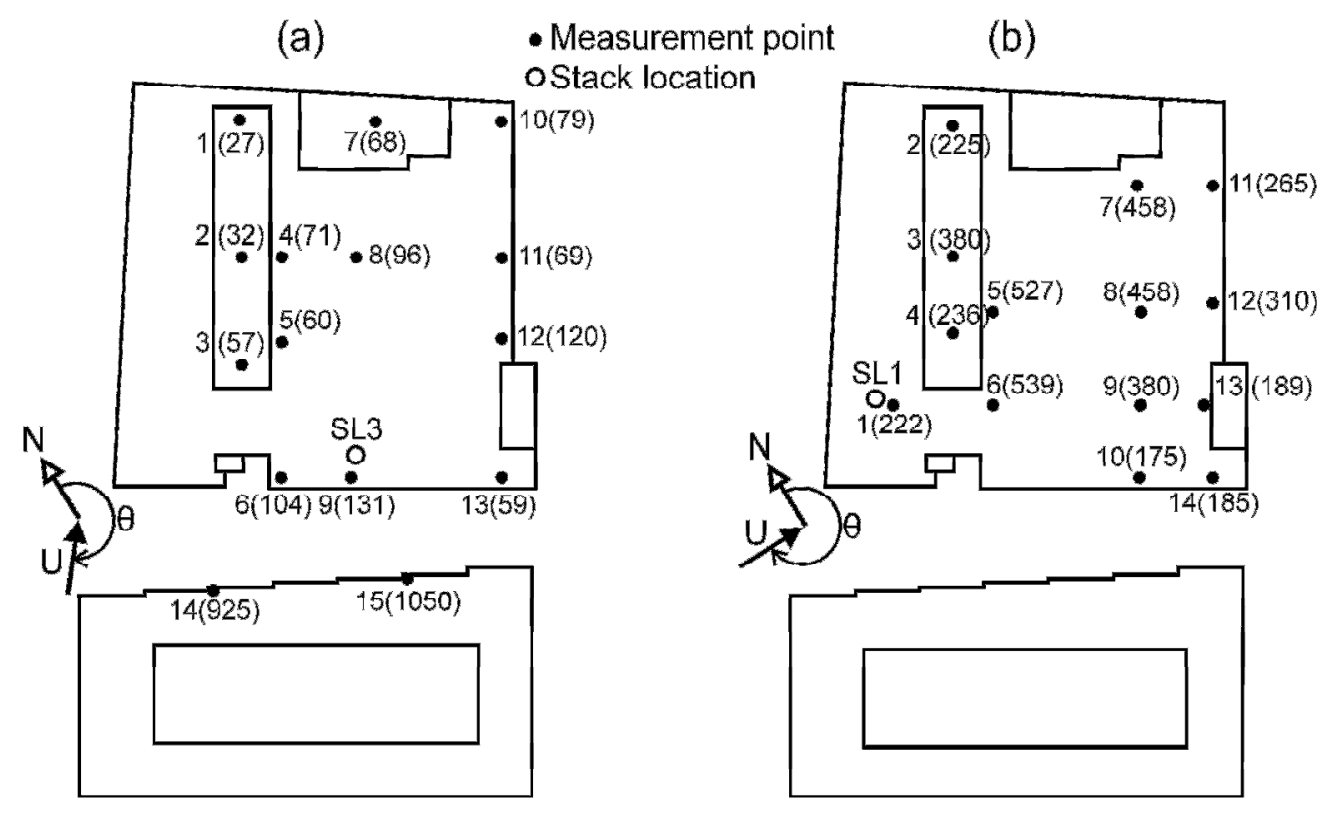


Fig. 4. Measurement points on the roof of the BE building and facade of the Faubourg building and measured concentration values $(100 * \mathrm{~K}$, between brackets) for (a) case SW and (b) case W. The stack location is indicated by SL3 and SL1, respectively.
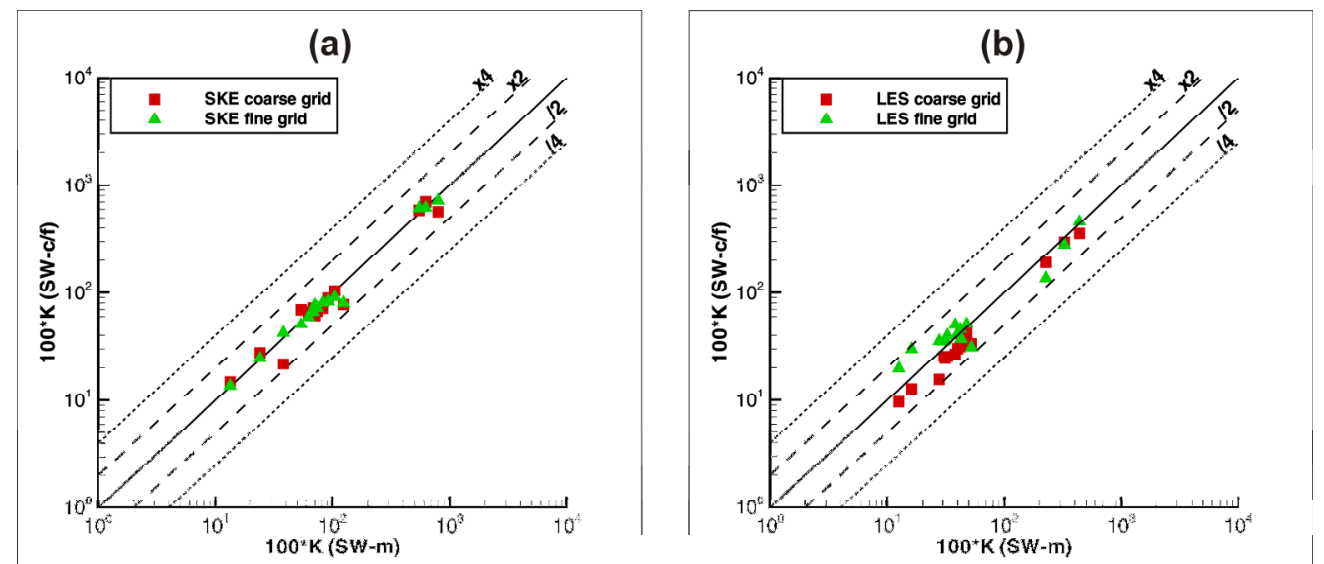

Fig. 5. Grid-sensitivity analysis: scatter plots of $100^{*} \mathrm{~K}$ values for case SW obtained with three different grids with (a) SKE $-\mathrm{Sc}_{\mathrm{t}}=0.5$ and (b) LES.
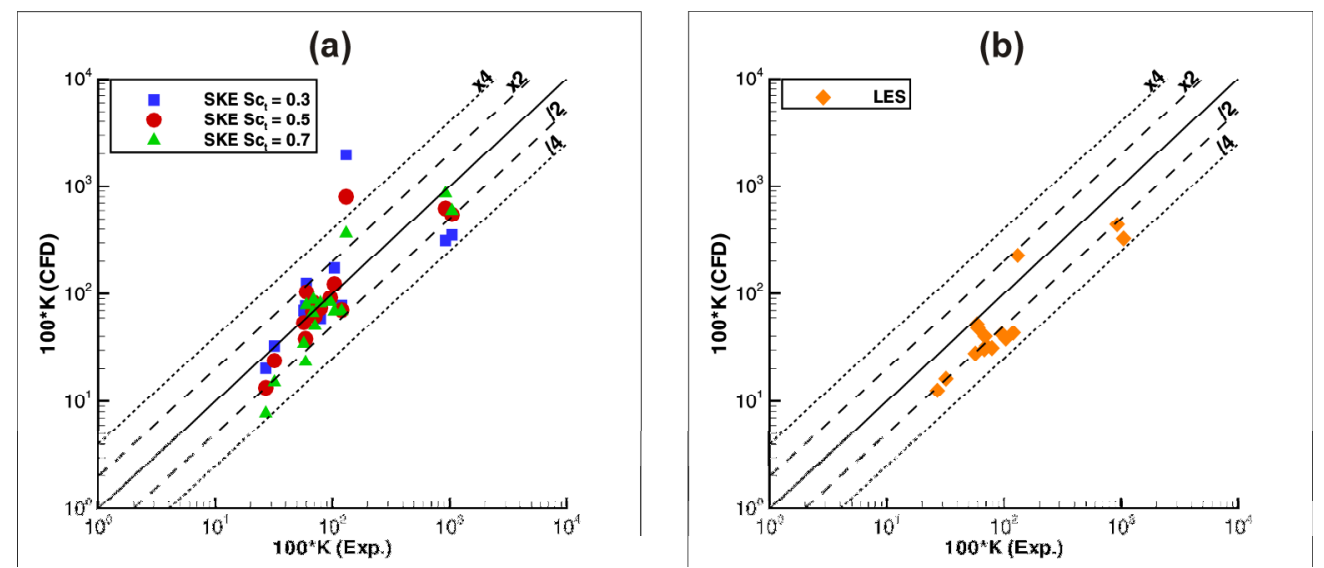

Fig. 6. CFD validation: scatter plots of $100 * \mathrm{~K}$ values for case SW with (a) SKE and (b) LES in comparison with experiments.
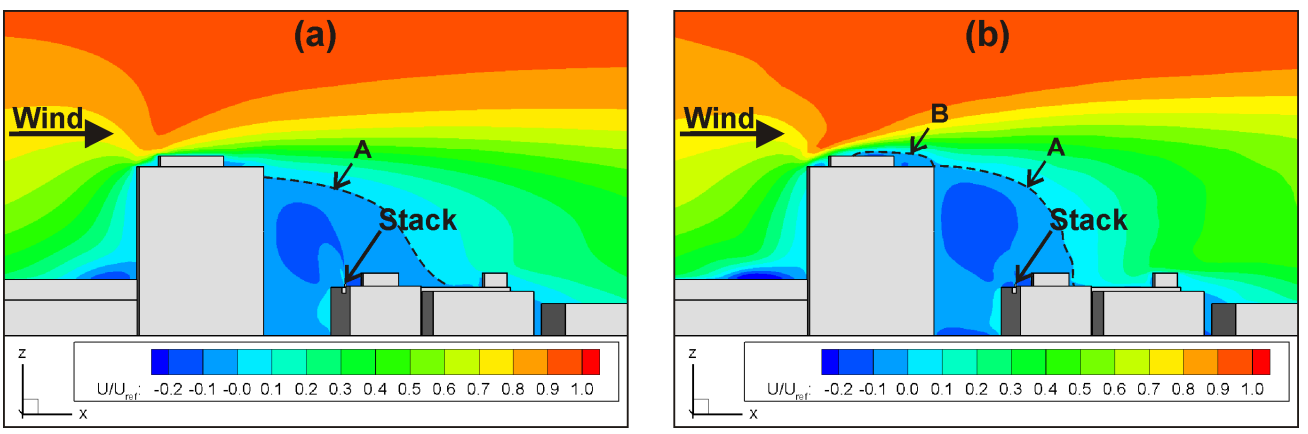

Fig. 7. Contours of mean streamwise velocity (non-dimensionalized by $U_{\text {ref }}$ ) in the vertical plane $y=y_{\text {stack }}$ for case SW obtained with (a) SKE and (b) LES. The dotted lines indicate the limits of the recirculation zones (A: wake; B: roof-top). 

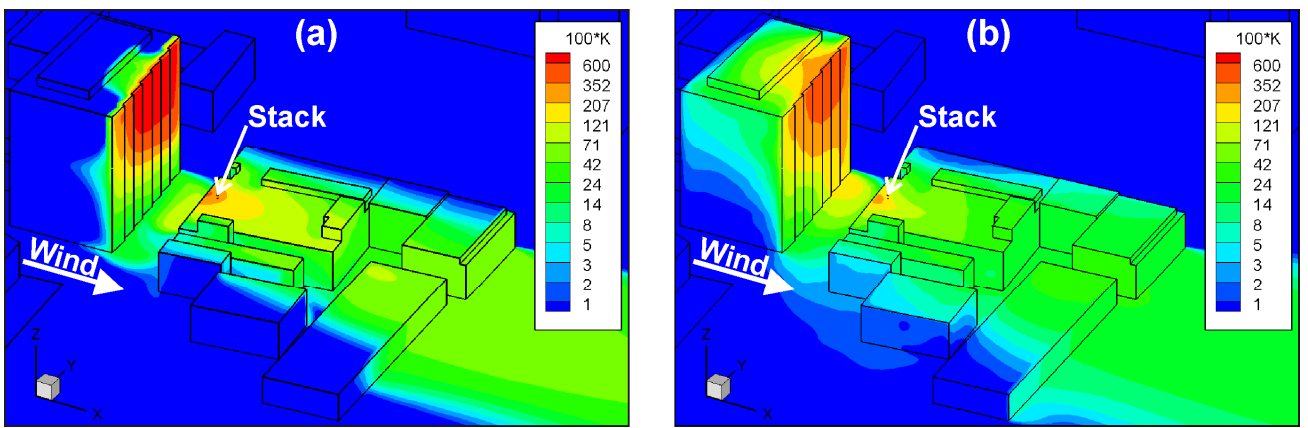

Fig. 8. Contours of $100^{*} \mathrm{~K}$ on building surfaces and surrounding streets for case $\mathrm{SW}$ obtained with (a) SKE - $\mathrm{Sc}_{\mathrm{t}}$ $=0.7$ and $(\mathrm{b})$ LES.
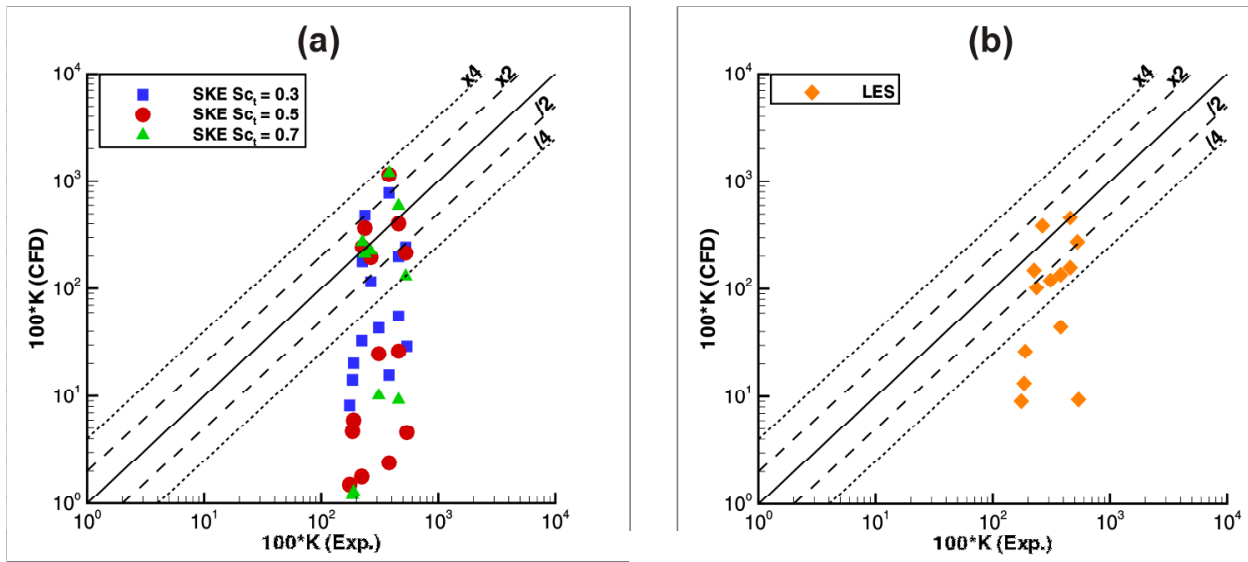

Fig. 9. CFD validation: scatter plots of $100 * \mathrm{~K}$ values for case $\mathrm{W}$ with (a) SKE and (b) LES in comparison with experiments.
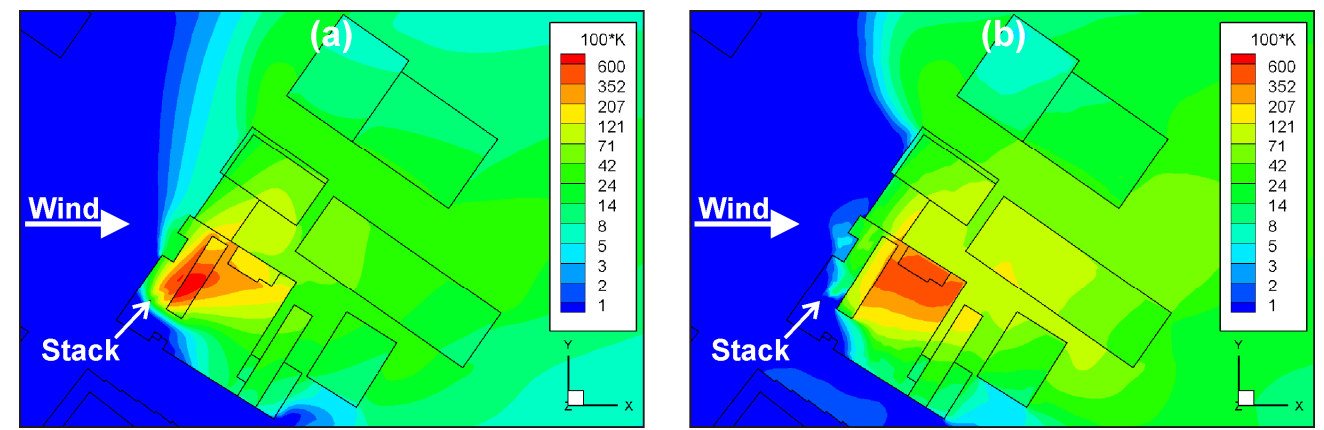

Fig. 10. Contours of $100 * \mathrm{~K}$ on building roofs and surrounding streets for case $\mathrm{W}$ obtained with (a) SKE $-\mathrm{Sc}_{\mathrm{t}}=$ 0.3 and (b) LES. 
TABLES

Table 1. Overview of previous and present LES computations of atmospheric dispersion in actual urban areas.

\begin{tabular}{|l|l|l|l|l|l|l|l|}
\hline Reference & City & $\begin{array}{l}\text { Spatial } \\
\text { extent }\end{array}$ & Closure & RANS & $\begin{array}{l}\text { Validation } \\
\text { by exp. }\end{array}$ & Cell type & Resolution \\
\hline $\begin{array}{l}\text { Camelli et } \\
\text { al. (2005) }\end{array}$ & $\begin{array}{l}\text { Tysons Corner, } \\
\text { VA, USA }\end{array}$ & Far-field & Smagorinsky & No & No & Tetrahedral & $\begin{array}{l}0.22-6.1 \\
\mathrm{~m}\end{array}$ \\
\cline { 2 - 7 } & USA York, NY, & Far-field & Smagorinsky & $\mathrm{No}^{\mathrm{a}}$ & $\mathrm{No}^{\mathrm{a}}$ & Tetrahedral & $\geq 2 \mathrm{~m}$ \\
\hline $\begin{array}{l}\text { Tseng et } \\
\text { al. (2006) }\end{array}$ & $\begin{array}{l}\text { Baltimore, MD, } \\
\text { USA }\end{array}$ & Far-field & $\begin{array}{l}\text { Scale- } \\
\text { dependent } \\
\text { Lagrangian } \\
\text { dynamic }\end{array}$ & No & No & Hexahedral & $\begin{array}{l}6-8 \\
\text { cells/buil- } \\
\text { ding }\end{array}$ \\
\hline $\begin{array}{l}\text { Patnaik et } \\
\text { al. (2007) }\end{array}$ & $\begin{array}{l}\text { Los Angeles, } \\
\text { CA, USA }\end{array}$ & Far-field & $\begin{array}{l}\text { Monotone } \\
\text { Integrated }\end{array}$ & No & $\begin{array}{l}\text { Yes (field } \\
\text { exp.) }\end{array}$ & Hexahedral & $6 \mathrm{~m}$ \\
\hline $\begin{array}{l}\text { Tamura } \\
(2008)\end{array}$ & Tokyo, Japan \\
\hline $\begin{array}{l}\text { Xie \& } \\
\text { Castro } \\
\text { (2009) }\end{array}$ & Far-field & N/A & No & No & N/A & N/A \\
\hline $\begin{array}{l}\text { Present } \\
\text { simulation }\end{array}$ & $\begin{array}{l}\text { Montreal, PQ, } \\
\text { Canada }\end{array}$ & $\begin{array}{l}\text { Near- } \\
\text { field }\end{array}$ & $\begin{array}{l}\text { Dynamic } \\
\text { Smagorinsky }\end{array}$ & Yes & $\begin{array}{l}\text { Yes (wind } \\
\text { tunnel) }\end{array}$ & $\begin{array}{l}\text { Hexahedral } \\
\text { (Body-fitted) }\end{array}$ & $\begin{array}{l}0.04-8 \mathrm{~m} \\
\text { (full-scale) }\end{array}$ \\
\hline
\end{tabular}

${ }^{\mathrm{a}}$ Comparisons with RANS simulations and field measurements of velocity vectors at several points in Hanna et al. (2006)

${ }^{\mathrm{b}}$ Details in Tamura et al. (2006), in Japanese

Table 2. Parameters for the two case studies.

\begin{tabular}{|l|l|l|l|l|l|}
\hline Case & Wind direction & $\theta\left(^{\circ}\right)$ & Stack location & $\mathrm{h}_{\mathrm{s}}(\mathrm{m})$ & $\mathrm{M}(-)$ \\
\hline SW & South-West & 220 & 3 & 1 & 5 \\
\hline W & West & 270 & 1 & 3 & 3 \\
\hline
\end{tabular}

Table 3. Main characteristics of the computational grids.

\begin{tabular}{|l|l|l|l|l|l|}
\hline Grid & $\begin{array}{l}\text { Nb of cells: } \\
\text { Total }\end{array}$ & $\begin{array}{l}\text { Nb of cells: } \\
\text { Stack } \\
\text { circumf. }\end{array}$ & $\begin{array}{l}\text { Nb of cells: } \\
\text { BE building }\end{array}$ & $\begin{array}{l}\text { Cell size at } \\
\text { other buildings } \\
\text { (m) }\end{array}$ & $\begin{array}{l}\text { Cell size at exterior domain } \\
\text { boundaries (m) }\end{array}$ \\
\hline SW-m & 4791744 & 32 & $130 \times 96 \times 49$ & 1.5 to 3 & 8 \\
\hline SW-c & 2860531 & 24 & $104 \times 77 \times 42$ & 1.9 to 3.8 & 10 \\
\hline SW-f & 6651874 & 40 & $164 \times 118 \times 60$ & 1.5 to 3 & 8 \\
\hline W-m & 5257343 & 32 & $136 \times 104 \times 51$ & 1.5 to 3 & 8 \\
\hline
\end{tabular}

Table 4. Average, maximum and median values of the relative error for case SW-m.

\begin{tabular}{|l|l|l|l|l|}
\hline & $\mathrm{SKE}-\mathrm{Sc}_{\mathrm{t}}=0.3$ & $\mathrm{SKE}-\mathrm{Sc}_{\mathrm{t}}=0.5$ & $\mathrm{SKE}-\mathrm{Sc}_{\mathrm{t}}=0.7$ & LES \\
\hline $\mathrm{e}_{\mathrm{AVG}}(\%)$ & 125.2 & 58.9 & 42.3 & 51.7 \\
\hline $\mathrm{e}_{\mathrm{MAX}}(\%)$ & 1406.0 & 508.9 & 178.8 & 73.5 \\
\hline $\mathrm{e}_{\mathrm{MED}}(\%)$ & 25.2 & 33.8 & 54.0 \\
\hline
\end{tabular}

Table 5. Dimensionless concentration coefficient $(100 * \mathrm{~K})$ and relative error values at each measurement point for case SW-m.

\begin{tabular}{|l|l|l|l|l|l|l|l|l|l|}
\hline \multirow{2}{*}{$\begin{array}{l}\text { Point } \\
\text { label }\end{array}$} & \multirow{2}{*}{$100 * \mathrm{~K}_{\text {Exp }}$} & \multicolumn{2}{l|}{$\mathrm{SKE}-\mathrm{Sc}_{\mathrm{t}}=0.3$} & \multicolumn{2}{l|}{$\mathrm{SKE}-\mathrm{Sc}_{\mathrm{t}}=0.5$} & \multicolumn{2}{l|}{$\mathrm{SKE}-\mathrm{Sc}_{\mathrm{t}}=0.7$} & \multicolumn{2}{l|}{ LES } \\
\cline { 3 - 11 } & & $100 * \mathrm{~K}_{\mathrm{CFD}}$ & $\mathrm{e}(\%)$ & $100 * \mathrm{~K}_{\mathrm{CFD}}$ & $\mathrm{e}(\%)$ & $100 * \mathrm{~K}_{\mathrm{CFD}}$ & $\mathrm{e}(\%)$ & $100 * \mathrm{~K}_{\mathrm{CFD}}$ & $\mathrm{e}(\%)$ \\
\hline 1 & 27 & 20.2 & 25.2 & 13.4 & 50.4 & 7.7 & 71.4 & 12.6 & 53.3 \\
\hline 2 & 32 & 32.7 & 2.3 & 23.9 & 25.2 & 15.1 & 52.9 & 16.2 & 49.4 \\
\hline 3 & 57 & 70.1 & 23.0 & 53.9 & 5.4 & 34.3 & 39.8 & 27.8 & 51.2 \\
\hline 4 & 71 & 69.7 & 1.9 & 62.3 & 12.2 & 50.0 & 29.5 & 32.7 & 54.0 \\
\hline 5 & 60 & 125.5 & 109.1 & 104.2 & 73.7 & 78.6 & 31.1 & 47.8 & 20.4 \\
\hline 6 & 104 & 174.2 & 67.6 & 124.0 & 19.3 & 68.8 & 33.8 & 38.1 & 63.3 \\
\hline 7 & 68 & 62.4 & 8.2 & 68.5 & 0.8 & 66.9 & 1.7 & 30.5 & 55.1 \\
\hline 8 & 96 & 90.5 & 5.7 & 91.6 & 4.6 & 84.3 & 12.1 & 42.1 & 56.1 \\
\hline 9 & 131 & 1972.8 & 1406.0 & 797.7 & 508.9 & 365.2 & 178.8 & 227.3 & 73.5 \\
\hline
\end{tabular}




\begin{tabular}{|l|l|l|l|l|l|l|l|l|l|}
\hline 10 & 79 & 59.5 & 24.7 & 74.0 & 6.4 & 81.7 & 3.4 & 31.3 & 60.4 \\
\hline 11 & 69 & 73.5 & 6.6 & 82.5 & 19.6 & 87.8 & 27.2 & 40.0 & 42.0 \\
\hline 12 & 120 & 77.7 & 35.2 & 70.6 & 41.1 & 69.2 & 42.3 & 43.1 & 64.1 \\
\hline 13 & 59 & 77.1 & 30.7 & 37.9 & 35.7 & 23.2 & 60.7 & 52.4 & 11.2 \\
\hline 14 & 925 & 314.3 & 66.0 & 624.2 & 32.5 & 858.3 & 7.2 & 439.7 & 52.5 \\
\hline 15 & 1050 & 354.0 & 66.3 & 548.2 & 47.8 & 596.0 & 43.2 & 327.2 & 68.8 \\
\hline
\end{tabular}

Table 6. Average, maximum and median values of the relative error for case $\mathrm{W}-\mathrm{m}$.

\begin{tabular}{|l|l|l|l|l|}
\hline & $\mathrm{SKE}-\mathrm{Sc}_{\mathrm{t}}=0.3$ & $\mathrm{SKE}-\mathrm{Sc}_{\mathrm{t}}=0.5$ & $\mathrm{SKE}-\mathrm{Sc}_{\mathrm{t}}=0.7$ & LES \\
\hline $\mathrm{e}_{\mathrm{AVG}}(\%)$ & 80.2 & 81.5 & 82.9 & 66.8 \\
\hline $\mathrm{e}_{\mathrm{MAX}}(\%)$ & 104.5 & 201.9 & 215.3 & 99.9 \\
\hline $\mathrm{e}_{\mathrm{MED}}(\%)$ & 88.6 & 95.6 & 98.7 & 64.9 \\
\hline
\end{tabular}

Table 7. Dimensionless concentration coefficient $(100 * \mathrm{~K})$ and relative error values at each measurement point for case $\mathrm{W}-\mathrm{m}$.

\begin{tabular}{|l|l|l|l|l|l|l|l|l|l|}
\hline \multirow{2}{*}{$\begin{array}{l}\text { Point } \\
\text { label }\end{array}$} & \multirow{2}{*}{$100 * \mathrm{~K}_{\text {Exp }}$} & \multicolumn{2}{l}{$\mathrm{SKE}-\mathrm{Sc}_{\mathrm{t}}=0.3$} & \multicolumn{2}{l|}{$\mathrm{SKE}-\mathrm{Sc}_{\mathrm{t}}=0.5$} & \multicolumn{2}{l|}{$\mathrm{SKE}-\mathrm{Sc}_{\mathrm{t}}=0.7$} & $\mathrm{LES}$ \\
\cline { 3 - 12 } & & $100 * \mathrm{~K}_{\mathrm{CFD}}$ & $\mathrm{e}(\%)$ & $100 * \mathrm{~K}_{\mathrm{CFD}}$ & $\mathrm{e}(\%)$ & $100 * \mathrm{~K}_{\mathrm{CFD}}$ & $\mathrm{e}(\%)$ & $100 * \mathrm{~K}_{\mathrm{CFD}}$ & $\mathrm{e}(\%)$ \\
\hline 1 & 222 & 32.9 & 85.2 & 1.8 & 99.2 & 0.1 & 100.0 & 0.1 & 99.9 \\
\hline 2 & 225 & 178.3 & 20.8 & 244.7 & 8.7 & 273.8 & 21.7 & 148.4 & 34.1 \\
\hline 3 & 380 & 776.6 & 104.4 & 1147.2 & 201.9 & 1198.3 & 215.3 & 135.7 & 64.3 \\
\hline 4 & 236 & 482.6 & 104.5 & 364.9 & 54.6 & 209.9 & 11.1 & 102.2 & 56.7 \\
\hline 5 & 527 & 244.5 & 53.6 & 214.3 & 59.3 & 130.9 & 75.2 & 274.8 & 47.9 \\
\hline 6 & 539 & 29.2 & 94.6 & 4.6 & 99.1 & 0.6 & 99.9 & 9.3 & 98.3 \\
\hline 7 & 458 & 198.1 & 56.7 & 401.4 & 12.4 & 593.4 & 29.6 & 458.1 & 0.0 \\
\hline 8 & 458 & 55.4 & 87.9 & 26.1 & 94.3 & 9.2 & 98.0 & 157.7 & 65.6 \\
\hline 9 & 380 & 15.7 & 95.9 & 2.4 & 99.4 & 0.3 & 99.9 & 44.2 & 88.4 \\
\hline 10 & 175 & 8.2 & 95.3 & 1.5 & 99.1 & 0.3 & 99.9 & 9.0 & 94.9 \\
\hline 11 & 265 & 115.7 & 56.4 & 194.8 & 26.5 & 224.4 & 15.3 & 385.2 & 45.4 \\
\hline 12 & 310 & 43.0 & 86.1 & 24.7 & 92.0 & 10.1 & 96.7 & 120.1 & 61.3 \\
\hline 13 & 189 & 20.1 & 89.4 & 6.0 & 96.8 & 1.3 & 99.3 & 26.2 & 86.1 \\
\hline 14 & 185 & 14.2 & 92.3 & 4.7 & 97.5 & 1.2 & 99.4 & 13.3 & 92.8 \\
\hline
\end{tabular}

